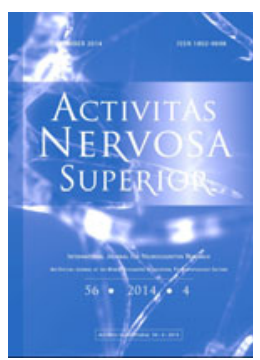

Journal

ANS: Journal for Neurocognitive Research

Homepage:

WWW.activitas.org

IDEAS \& OPINION

\title{
KNOWLEDGE, SCIENCE AND DEATH: THE THEORY OF BRAIN-SIGN
}

\author{
Philip Clapson* \\ Department of Psychological Sciences, Birkbeck, University of London
}

\begin{abstract}
In today's paradigmatic climate, the possibility of knowledge, and therefore science, still depends upon our being conscious. However, no scientifically accepted account of consciousness exists. In recent years I have developed the theory of brain-sign which replaces consciousness as a wholly physical neural condition. The first tenet is that the brain is a causal organ, not a knowledge organ. The second is that brain-sign, used in inter-neural communication for uncertain or imprecise collective action, derives at each moment from the causal orientation of the brain. Signs are ubiquitous bio-physical entities. Thus there is no problematic dualism, consciousness and world. We now have two accounts of the brain phenomenon. The first (consciousness) is an inexplicable physical anomaly. The second (brain-sign) belongs in the physical universe, and fulfils a crucial neurobiological function. With brain-sign theory we even 'discover' that we do not know we are alive or will die.
\end{abstract}

Key words: Brain-sign; Consciousness; Collective action; Eliminativism; Inter-neural communication; Interorganism communication

\section{INTRODUCTION: A MATTER OF LIFE AND DEATH}

Quite early in life we realize we will die. Our response can be disquieted, perhaps terrified. How could this precious life end? But if we were never alive, death would lose its significance because what we suppose we lose never existed: therefore with our (purely physical) body's demise we have lost nothing. How could this be? Is it a quibble about what is meant by death, or its medical classification - the heart stopping, or absent brain function? No. The question is: Do we in fact know we are alive?

We do, it is commonly supposed, because we are conscious. If we cease to be conscious, other than temporarily by being asleep, or maybe in a coma, then we are dead. We can never know anything again. But is the apparent presentness of ourselves to ourselves which confers the understanding of our condition as conscious and therefore alive, indubitable? To verify our state might seem to require that we step out of ourselves to confirm our condition - which is impossible. Our conviction lies solely in our self experience: its joys and pains; our command over the world by skills acquired. But is the sense of conviction enough, or is it part of our predicament?

Whether we know we are alive may be approached by science - a means of setting up theories about the physical universe, of testing them and establishing quantification.

${ }^{*}$ Correspondence to: Philip Clapson, e-mail: p.clapson@bbk.ac.uk

Received September 10, 2014; accepted October 30, 2014; Act Nerv Super 56(4), 105-120; ISSN-1802-9698 
However, we are immediately confronted by the problem that our sense of being conscious does not conform to current theories about the physical universe: matter and cause-effect. No link has generated a scientific model, in Thomas Kuhn's (1996) notion of 'normal science' - i.e., one agreed by the scientific community. This is exceedingly problematic because it is widely assumed that theories are developed and known by our being conscious of them. ${ }^{1}$

More fundamentally, and in spite of our supposed advances in knowledge of neural material, there is no explanation of what self presence is in any scientific sense. The only justification is that it occurs as us. It is self-confirming. But this is hardly sufficient because what we are trying to identify (knowledge) is embedded in the condition we presuppose as the means of identification (consciousness).

In this paper I offer a scientific solution based on understood physicality, and with biological necessity. It is termed: The theory of brain-sign. It avoids the conundrum of our self presence in the universe by eliminating our existence, in the consciousness sense, from the universe. According to the theory, nothing about us transcends physicality as currently understood. Then understanding, knowledge and science will be addressed. Then death itself.

\section{A. LOCATING THE DEPARTURE POINT OF THE MODEL: HISTORY}

The problem of the conscious mind is generated in its history. How can we, as mind, know anything about the world? Empedocles ( $5^{\text {th }}$ Century BC) proposed that visual knowledge was gained by the conjunction of rays (effluences) emanating from the mind and from the object. Mind and world, the inner/outer division, was thus given a proto-scientific explanation.

Aristotle, by contrast, proposed a causal account of seeing in which the eye takes the object's form from the presence of the object. Since seeing invokes a representation of the object, Empedocles' physical link between object mind was broken. In this way error (which we know we suffer) was addressed because misrepresentation of the object can occur, which Empedocles' account makes impossible.

Brentano's notion of mentality, while acknowledging Aristotle as a source, was misguided. In the heritage of the Empiricists, ${ }^{2}$ who had adopted the notion of an inner mental representation of the object, he supposed representations were seen, rather than that seeing was itself representational, which was Aristotle's probable position. Brentano identified intentionality (the ability of the mind to be directed towards its representations) as a nonphysical mentalist account addressing presence in absence, e.g. the object could be imagined without being present. But his theory was criticized by Husserl for its Empiricist inheritance.

Husserl avoided Empiricist representation, which could not fully account for how the inner representation could correspond to the object since the direct link between object and representation had been broken, and he accorded to mental states the power of directedness upon the object per se. This addressed other mental states than seeing for, as with Aristotle, directedness lay in the particular mental act: seeing, imagining, wishing, hoping. Consciousness was a meaning (Sinn) phenomenon.

Husserl's phenomenological reduction (discounting the world we presuppose in our seeing, together with reflective focus upon the condition of the seeing condition itself) was the means of investigating mental life directly. Ordinary seeing in the natural attitude, Husserl proposed, is an uncritical assumption about the presence of the world without reflection on how, and in what way, it comes to be for us. Thus Husserl proposed that his Transcendental Idealism should be the foundation for philosophy and science because it is how the world can be examined,

\footnotetext{
${ }^{1}$ In his recent book, Luiz Pessoa quotes Francis Crick as saying, in analogy to consciousness: "There was never a time in the history of biology when a bunch of us sat around the table and said, 'Let's first define what we mean by life"' $(2013$, p. 4). The inability to define consciousness as a bio-physical condition is, of course, the central problem for the scientific status of mentalism.

${ }^{2}$ Locke, Berkeley, Hume.
} 
based upon that which gives us the world (the world in fact). Husserl considered he had solved the inner/outer conundrum.

But Husserl's invention cannot be a scientific solution because his model presupposes that, for the mental subject, phenomenological complexity works without relation to the physical world described by science. The world has ontologies. Consciousness is apophantic: it gives the world, but not in terms of the world. As Quentin Lauer has said: "Phenomenology began as a quest for objectivity, but what it has done is to define objectivity in terms of what it has found" (1965, p. 65). Mind as divine, and its elevation from nature, remains from its earliest human origins, at least implicitly. ${ }^{3}$

\section{B. CURRENT PERSPECTIVES}

Current discussion of the reduction of consciousness to the brain, or emergence from it, is generally ineffectual since what we want to know first is not how it can be in or from the brain, but what it is in terms of the physical world. But there is no consensus about what consciousness is, or how it is to be defined or described.

The key function of consciousness, hypothetically, is as knowledge: otherwise the brain appears to be states of matter generating physical causality. But to suppose we can know consciousness is knowledge is, de facto, to suppose consciousness exists so that we can know it does. In his review of a recent book by Antonio Damasio, John Searle claims that "We know consciousness happens and we know the brain does it" (2011). Searle apparently feels no need for justification.

We can take Searle's tautological assertion further. For it is reasonable to suppose that most writers and readers of texts about consciousness implicitly assume (perhaps one should say culturally assume) that what is written or read about consciousness can be understood because consciousness is where reading and writing happen. ${ }^{4}$ So intrinsic to our lives is this that the need to justify consciousness's existence, rather than assuming it, would seem essential.

Searle's assertion appears to ascribe a causal origin to consciousness. "I am conscious: I am making a statement about consciousness with which you concur. 'We know consciousness happens.'" It assumes a match between Searle and his audience in what he has elsewhere referred to as "an inner, first person qualitative phenomenon" $(1998$, p. 5). Without stating it, this is a claim about a functional role of consciousness in rendering inter-human agreement about an objective judgment of the world, which includes consciousness.

Moreover, Searle has said that "Consciousness is above all a biological phenomenon, like digestion or photosynthesis" (ibid., p. 175). Consciousness, therefore, should be a causal origin in neural functioning. But digestion and photosynthesis fit, as science, within an agreed biophysical model. Consciousness does not. Therefore his claim stands isolated from any other aspect of the physical universe, including our biology. How can a perception, a thought, a feeling be causal? Searle simply says it is a 'mystery' $(1998 ; 2011) .{ }^{5}$ Searle's is not the only approach. Philosophical attempts to show how consciousness, as a concept and phenomenon,

\footnotetext{
${ }^{3}$ The claim of the Phenomenological position - that the phenomenological state is primary in revealing the world exists in variants, including that of Heidegger, whose ontology diverged from Husserl.

${ }^{4}$ This is not a circularity presupposing consciousness and its knowledge of the world, as found in, for example, Varela, et al. (1991, p. 3 and below).

${ }^{5}$ The global workspace theory of consciousness, i.e. consciousness as a global source of information in the brain, proposed by Bernard Baars and others, does not explain either how the brain generates such a condition, or how non-conscious, or more accurately purely neural programs, can interact with it. Claims that fMRI scan data supports the theory are inappropriate because the model is itself inadequate (e.g. Baars, 1997).
} 
could or could not be a physical brain condition include, conflictingly-monist/dualistreductive/non-reductive-identity/supervenient-illusion/non-illusion versions. ${ }^{6}$

However, Colin McGinn has famously said that "A deep fact about our own nature as...embodied consciousness is...necessarily hidden from us" (1989, p. 366), thus classing these attempts as futile.

There are neuroscientific attempts by Gerald Edelman and Giulio Tononi (2000, p. 139 and below). They proposed the Dynamic Core hypothesis that consciousness is generated by reentrant and interacting dense clusters of neuronal groups with distinct functional borders. The significance of causal density and integrated information has been further developed by, e.g., Anil Seth et al. (2011). Francis Crick and Christof Koch (1990), on the other hand, proposed $40 \mathrm{~Hz}$ neuronal synchronous oscillations as possibly responsible for visual awareness and visual binding, but subsequently decided it was inadequate. And there are various writers' accounts from quantum theory, including Roger Penrose (1989), although, these hope for an escape from physical determinism thus enabling free will.

If a scientifically expressible solution existed, opinion would likely coalesce around it. However, the methodological problem from the philosophical standpoint is that, despite differences of ontological description, consciousness is almost universally unquestioned. As McGinn says, "embodied consciousness" is "our...nature", but "hidden". But what exactly is our nature? From what is it hidden? On the other hand, neuroscientists generally consider consciousness self-evident. ${ }^{7}$ That philosophers bother about its characteristics is irrelevant.

\section{GROUNDWORK FOR THE BRAIN-SIGN MODEL}

An option exists to enable a science. The brain phenomenon is not consciousness: it is a physical state expressible in neural terms. Its biological function does not conflict with the causality of the brain. No subjective/objective distinction obtains. Moreover it explains how theories arise, including its own. It explains why the notion of consciousness, and the mind, came to be. This is the theory of brain-sign.

We do not start with what has seemed natural, the philosopher's statements and our assumed mutual agreement about them. Our concern is what causes the philosopher's statements, what do they comprise, and what function do they perform? - as a physical brain. This approach, of course, dislodges the philosopher's significance in terms of his/her supposed operation as a person: imparting opinions and knowledge. We are now in the physical world which operates without persons or consciousness. (In proposing that Searle is incorrect, we do not suppose greater wisdom. The brain knows nothing of opined superiority. $)^{8}$

Let us begin by considering a description of the brain reacting to the world in neuroscience terms. Information from the optic tract enters the primary visual cortex (V1) via the lateral geniculate nucleus (LGN), which bifurcates into the ventral and dorsal streams. Information

\footnotetext{
${ }^{6}$ Revealingly, Susan Schneider's 2011 book begins with these two sentences. "Minds, whatever these are, are the bearers of mental states. And it is the primary ambition of philosophy of mind to figure out the nature of minds and their states" (p.1). Emphasis added.

${ }^{7}$ Hence the minimal attention paid to it in books on Cognitive Neuroscience.

${ }^{8}$ This unacknowledged issue undermines Paul Churchland's (1981) paper eliminating propositional attitudes. He depends upon a future completed neuroscience which nevertheless requires the transcendent function of consciousness for it to be comprehended. This position remains in his recent work in which consciousness (without scientific definition) is identical to the brain to save philosophy from physicality. There is no 'objective' criterion a variant of the Platonic heaven - against which it could be so judged. Yet Churchland appeals to such criterion by discounting pragmatism (2007, p. 103). "While I am at least a closet pragmatist, and while I resonate to the idea that the brain's cognitive activities are ultimately in the service of motor control [i.e. action], I balk at any such direct definition of the sort proposed... Specifically, if we define or identify what counts as truth, or as knowledge, in terms of the behavioral success it produces, then we will not be able to give a nontrivial explanation of those behavioral successes in terms of cognitive representations that do give rise to the level of knowledge and truth."
} 
ascends from the primary areas into higher cortical regions. Aspects of the initial stream of information are processed in different ways in the hierarchy of interconnected regions. Feedforward, feedback and lateral processing ensures the regions "cooperate and constrain each other to resolve conflicts and produce a consistent interpretation of the world" (Mareschal et al., 2007, p. 108). In different regions of the brain it has been subjected to processing of shape, color, texture; and whether it is a face or a house - i.e. distinctions according to biological significance. The interpreted object 'emerges' from this processing.

The description is stripped of complexities and debates, but will serve our purpose. It appears to make the same demand on us as do philosophers. Physical processing is couched in informational terms which is to be understood because, being conscious, we grasp the notion of information. It refers to shape and color, faces and houses, which assumes we know what the brain is responding to as the world, as well as locations in the brain, which are also in the world. In other words, we understand what the brain is doing because we know, independently of being a brain, of shapes and colors and houses. (Kant's things-inthemselves.) But our position cannot be outside the brain. In itself the brain knows nothing of information or the world per se: it is purely physical material.

Finally, the description refers to the emergence of the interpreted object. However the description only proposes that physical states are modified in reaction to the object in the world. Does the brain create/grasp the emergent object as a conscious state of the world? Why, when the brain has before it the world to which it is progressively adapted, does it need an additional conscious representation of it?

So, assuming consciousness does not exist, the neuroscience description would seem to be the brain's communicative activity with other brains. Therefore we require a model which explains neural communication independently of the notion of consciousness.

Antonio Damasio has said that:

"Consciousness is just the latest and most sophisticated means of generating adequate responses to an environment...by making way for the creation of novel responses in the sort of environment which an organism has not been designed to match, in terms of automated responses" (1999, p. 304) (slightly reconstructed) which it does by "the world of planning, the world of formulation of scenarios and prediction of outcomes"(ibid., p. 303).

But this supposes that consciousness is expressing itself from itself. Since no physical model is offered, Damasio must endorse an unexplained magic by which the physical brain transmogrifies into another condition (consciousness) which is not physical automation. ${ }^{9}$ And since the brain knows no more of itself than of the external physical world, it must be the brain expressing itself. Thus, to develop an effective model we must discard explanations which resort to divinity or magic, even implicitly, and remain within the physical world of which brains are a highly organized segment.

The condition which has misled philosophers and others for millennia is apparent in this discussion. How can we as mind (pre-Socratics), thinking thing (Descartes) or realm of meaning (Husserl), obtain the world we see, understand or ponder?

A progressive answer for science is that we do not: there is no mind, etc., and it does not reach out to, nor is it directed-towards its subject matter (intentionality). Our supposed transcendence over nature is a scientific mistake. But it is a mistake from our biology - a mistake we cannot help making.

In the sight-related physical model of the previous section we reached the point at which the brain had responded to an external scene. But we stopped short of that being consciousness. Now we make a complete departure from the history of mind, and the need to explain it. Our concern is with the physical brain.

${ }^{9}$ Often referred to as 'the explanatory gap'. 


\section{THE BRAIN-SIGN MODEL}

Social cognition has become a major topic of philosophy, psychology and neuroscience. The problem for theories of social cognition is, however, that they are constrained by the problem of mind. Do we have a theory of other minds? Do we simulate other minds? Do we engage with other minds? Do we interpret the other's physical movements? There remains a requirement for an inner realm of mental being whereby we can respond to, or relevantly act with others, by our mind grasping their mental condition and its intentions..$^{10} \mathrm{If}$, on the other hand, we remove the mind, we both allow the brain to do its work, and we can identify the ontology and function of the brain phenomenon misconceived as consciousness. What work does the brain do? What is the role of the brain phenomenon?

\subsection{The forms of organismic communication}

Two relevant points can be taken from the recent book by the major figure in Sociobiology, Edward O. Wilson. He states that:

"Through further evolution the Mesozoic ants went on to build little civilizations by instinct, spreading their domain everywhere through the rotting vegetation on the surface and deep down into the soil beneath. They evolved in complexity while proliferating new species during tens of millions of years" (2012, pp. 115-116).

Firstly, social activity exists, improving survival and reproduction. It existed long before the emergence of humans. Secondly, the interaction between members of a community at the ant level is by instinct. The word 'instinct' entails no mind entering the operational frame to influence activity moment by moment. Collective activity, and the means of communication, are genetically established, and carried out by purely, or in Damasio's word 'automated' physical means. They have evolved and been sustained over millions of years.

In like manner, but with extraordinary relative complexity, are bees and their dance-like behavior. Forager bees sign and responder bees alter their behavior to store more honey or go off to seek the signified source of nectar. They do not think about what they are doing: the signing generates the effect directly (if it works).

Brain-sign theory refers to this type of social interaction (often termed Eusociality), which generates a specific end, as static communication. It operates through sense organs and is activated brain-to-brain via the interposing physical media. These can be the secretion of chemicals with molecular transmission; for bee behavior it depends on instructional signs carried via electromagnetic radiation or compression waves. Who does what depends upon their organizational role. Although the organisms appear to be spatially separate individuals, their activity is bound together as one physical unit by the genetically established use of the interposing physical media. Hence the somewhat vague term, superorganism. Brain-sign theory terms this collective activity: the unit of the communicated.

But communication in the biological realm is not solely pre-programmed and rigid. It can depend upon interaction between organisms to generate a result which is not necessarily or structurally pre-established. Much of human communication has this flexibility, and it is a very significant biological development. It is referred to as dynamic communication. For this, brain-sign has evolved.

\footnotetext{
${ }^{10}$ There are metacognitive models concerning mentalist communication (e.g. Shea et al., 2014), but they do not address consciousness. There are theories about the social construction of mental life (e.g. Prinz, 2012), but these do not address mental states as physical properties of the brain. The book by Semin and Echterhoff (eds.) titled Grounding Sociality, concerned with neurons, mind and culture, asks "how do [individuals] share their innermost states like their thoughts?" (2010, p. 2), on the supposition that minds are a prerequisite. But since there is no explanation in any of the articles of a link between neurons and minds, grounding has not occurred.
} 
The question is: How does flexible collective behavior, with its requirement for dynamic communication, operate? The cooperation of bees and ants depends upon the interposing media. Its efficacy depends upon those media as conveyors of signs. Surely the same requirement exists for dynamic communication. But precisely because the cooperation is uncertain or imprecise, for example it can change rapidly as two lions pursue a gazelle on the African plains, the signing cannot be a form of control one over the other. ${ }^{11}$ Neither lion 'knows' what will happen next which could generate a determining sign to the other. The movement of the gazelle and lion B determines the behavior of lion A via its neural reception of electromagnetic radiation from their rapidly moving forms.

The causal operation of the brain generates the movements of the lions, as of the gazelle. But since signing is a necessary requirement of cooperative activity, neural causality cannot be effected without it. What binds the activity cannot be determining signification, as in static communication. Rather, because of the indeterminacy of the activity's unfolding and outcome, binding is a mechanism of continual neural self-explanation. What is to be explained? Each lion's brain explains the cause of its current movements. How does that explanation take place? It does so by what in the world has caused its brain to generate the current movements. What determines that explanation? The brain's causal orientation towards the world established in its neural operative structure. In other words, the brain interprets its own causal orientation toward the world, forming it into a sign. That signifying neural explanation I call brain-sign. ${ }^{12}$ Signs are a biological commonplace: the chameleon's changing skin, the cat's waving tail, bird song, even the shape of a stick insect or flat fish.

Although brain-sign is an explanation, it is not an explanation to anything or anybody. Use of the words 'sign' and 'explanation' are a temporary expediency between writer and reader. Crucially, no lion reads another's mind. The gazelle 'image' signifies the common target in the unit of the communicated, the capturing, killing and eating of which will result in the satiation of the physiological requirement for food energy.13 Neither lion's brain knows this. What is also signified in lion A's brain is lion B, and the texture of the plain upon which the hunt takes place, because these are elements incorporated into the hunt process.

However, the significance of the gazelle is causally distinct from the physical environment because it is the source of energy. The significance of the environment is that it has to be negotiated in the hunt process. The significance of lion B to lion A's brain is its cooperative movement in the hunt process, as well as its bio-physical coexistence. This description of the modus operandi of a changing neural structure, fulfilling a biological program across the contours of the brain, is entirely different from the problematic notion of knowledge, for it explains the brain's causally differentiated orientation, selected in time, towards features of the world as signified. No requirement to explain visual knowledge as input to a cognitive mechanism, as a physical property, is required. ${ }^{14}$

Crucially, if the gazelle signification ceases for any significant time in the neural fabric of either lion, the hunt, as one physical cooperative unit, has ended. (The actual causal conditions in the brain cannot be a sign because of their complexity and differences.)

\footnotetext{
${ }^{11}$ In his book Open Minds, Wolfgang Prinz uses chasing lions as an example of our inference that the lions function with minds. However, he does not explain how this could happen in a neuroscientific sense, e.g. what a perceiver or perception is neurally, or indeed inference (2012, p. 56 footnote).

${ }^{12}$ The term was first used by Charles Sanders Peirce in a paper in 1868, but was not functionally developed as here.

${ }^{13}$ Throughout the subsequent text, inverted commas about a word, as here 'image', indicates that a mentalist term is being replaced by brain-sign. Thus the reader can identify that this is an alternative use of the familiar word. When brain science is further developed, this will not be needed. Incidentally, we still use planetary names though what planets are and do has entirely changed from the geocentric usage.

${ }^{14}$ What Susan Hurley (2008) has referred to as the "classical sandwich conception of the mind", initially attacked as 'The Myth of the Given' by Wilfred Sellars (1997). Note, also, that this account is not that of J. J. Gibson's affordances, since the function of the representation is not any kind of cognitive input.
} 


\subsection{The physical status of brain-sign}

This account addresses both problems of representation and the possibility of error. The sign is a representation, but it is not to be judged by its relation to truth. The relevance of the signification is not the world represented, but the causal orientation of the brain towards the world as signified. As a bio-physical condition, error can occur because the representation derives from the brain's causal orientation. The 'gazelle' may be a mirage caused by foliage which is misinterpreted by neural processing which has been substantially pre-established over time by engagement with the world (e.g. Gerald Edelman's notion of 'the remembered present', 2000). If so, the lions' initial brain-sign dissolves as they move, and that course of action has been abandoned.

Thus brain-sign is not knowledge and has no causal function for the individual brain. But the brain phenomenon is not epiphenomenal, as Ray Jackendoff once proposed (1987). It has a crucial neurobiological role.

In mentalist terms you and I may look at a tree. But the brain does not look at trees. Placed before a tree, its neural fabric is affected to generate a causal response. We have no access to that as the brain phenomenon. As brain-sign, we are the 'sense' that we do see the tree. Our supposed seeing is a neural communication between our brains of the world toward which they are mutually causally orientated, even if no bodily action is carried out. (The word communication deriving from the Latin communicāre, to share.) If there is action, for example we move closer to pick its apples, 'we' as brain-sign will modify accordingly. The apparent seeing has the character of definiteness or stability we take as the 'experience-of': for example, we 'take $i^{\prime}$ ' the 'experienced' tree really is a tree and is there. 'Our supposition' is part of the sign, not a condition elevated from 'our' physical encasement.

Brain-sign theory, therefore, is a new neurobiological account of organismic functioning. It eliminates mind as a myth founded upon an inner domain of knowledge. Brain-sign occurs in the neural fabric of the brain in a way yet to be specified. As a sign, it can be directly explained from its physical instantiation.

Of course we cannot get outside our brains to confirm this is so. But we cannot do so for consciousness either, which therefore cannot be considered, de facto, a better explanation. Indeed, consciousness has no non-tautological biological rationale. Consciousness tells us we are conscious! Brain-sign, however, arises as a biological necessity in neural function. ${ }^{15}$ We are essentially communicating organisms, and brain-sign is the physical/functional means by which that takes place. ${ }^{16}$

As said, seeing or perception would appear to be unnecessary since the brain already has its domain of action directly in front of it. ${ }^{17}$ Thus we have removed the conundrum of the inner/outer and how they correspond.

\subsection{What 'subjectivity' really is}

Now the question arises: What about our self presence? Surely it is we as mental subject who is aware of the lions and gazelle, and ourselves being aware. But this is now physically resolvable. As with the consciousness assumption underlying the writing and reading of texts

\footnotetext{
${ }^{15}$ This is not the same as George Herbert Read, and others, who propose consciousness exists to fulfil a social function.

${ }^{16}$ It might seem presumptive to call brain-sign a theory rather than an hypothesis. However, there is as much evidence of brain-sign's existence as of consciousness. Indeed, since it is based entirely on established physical principles, it is more likely correct than consciousness. Yet we now see departments in universities set up for what is termed consciousness science.

${ }^{17}$ This is not a new idea. It is described thus by Peter Machamer: "Suppose the atomic elements (individual axon or dendrite processes, say) don't have content but respond differently to different inputs connected directly or indirectly to environmental influences..." $(2009$, p. 173). However, brain-sign theory is not a Behaviorism.
} 
(as in section 2B), we do not directly grasp the encompassing physical model of self presence because the ' $\mathrm{we}^{\prime}$ ' is within the model with the lions and gazelle.

The subject, or self, has a checkered history. For Kant, the subject was the foundation of the very possibility of consciousness. But in brain-sign theory the 'subject' (the 'sense of our self') is simply a representation of the body in its causal orientation toward the world. The body is the whole possibility and actuality of action. ${ }^{18}$ When we appear to observe the lions and gazelle, 'we' (our 'sensed self') and 'what we see' are a unified brain-sign. Our 'sense of being an observer' of a scene is actually a representation of our body's causal orientation towards the particular immediate world (in this case the lions' chase).

As to the supposed awareness that we are a self watching the scene, this is a brain-sign state signifying the body's condition in the world. " $\mathrm{I}$ ', my body, is currently causally related to the chase." It is not a self-revelation of an inner mental state: it exists for collective action and is extensively expressed in language. "I am looking at the chase."

We have no 'sense' that our ' $I$ ' is the represented body because brain-sign is a representation of the causal neural condition to which 'we', as brain-sign, have no access. This account therefore eliminates the subject reflecting upon itself in its isolated mental world. Instead it explains, biologically, the 'sense of the self' (as in section 1): not a mental I, but constantly represented bodily causality. This explanation removes the I as primary in my experience. Experience, as the so-called 'what it's like', with the problematic condition of phenomenality dwelt upon by (e.g.) Thomas Nagel, David Chalmers and Ned Block, can be discounted, and thus de-problematized. ${ }^{19}$ The mental I does not exist, but ' $I$ ' feature in brainsign.

The relation between body and world, in its complexity, is represented by brain-sign. It is never neutral - there are always more or less obvious (bodily) reactions to the world concurrent with its graphical representation. These states have been termed sensations and feelings, etc. For example, the 'thrill' of the chase. (This contradicts Bennett and Hacker, who say: "Seeing an ordinary table or chair does not evoke any emotional or attitudinal response whatsoever in normal circumstances" (2003, p. 40).)

\section{A BRIEF REVIEW}

Brain-sign theory includes the bodily reaction to the world, commonly considered in terms of sensation or feeling, as mentioned in the paragraph above (see further Clapson, 2012). However there are more topics to address before returning to our opening theme. First a brief review.

1) That we are convinced we see, think and feel is not denied by brain-sign theory. These 'appear' real because that is how biology executes its function. If 'we thought' otherwise, brain-sign would fail. It is the theory of consciousness that is incorrect. ${ }^{20}$

This draws us to the conclusion, exemplified by the hunting lions, that cognition, hypothesized as a causal function of mental states and essential to the disciplines of cognitive science and cognitive neuroscience, is a mistaken view of brain operation. More likely, the brain operates by neural programs which employ the communicative role of brain-sign. ${ }^{21}$

\footnotetext{
${ }^{18}$ As Friedrich Nietzsche said: The "body and its great intelligence...does not say 'I' but performs 'I'” (1961, pp. 61-62)

${ }^{19}$ In Chalmers' words: "The really hard problem of consciousness is the problem of experience" (1995-7, p. 10). But this is a particular use of the word 'experience' for a contentious philosophical position.

${ }^{20}$ The parallel with the geocentric and heliocentric theories is obvious.

${ }^{21}$ While David Eagleman reasonably says that "internal data is not generated by external sensory data but merely modulated by it" because the brain "is properly thought of as a mostly closed system" $(2011, \mathrm{p} .44)$, he fails to identify a cogent bio-physical role for consciousness (the notion it is the CEO of the brain entails no physical explanation), and relies on its emergence which he cannot explain (as with Daniel Dennett).
} 
2) In the modern view of mind (generally), the surface mental structure has, somehow, to be imposed upon or derived from the physical brain. It has seemed a crucial endeavor because only then can our self-image as mind be preserved. (This will be further discussed in section 6.) Brain-sign theory replaces the mind. Locating the mechanism of the neural operation for brain-sign is a task for neural science.

3) The physical world is invisible to us, both because we do not see it, and because the 'sense' we see it has no causal impact upon what we individually do. Since brain-sign is a neural signifying representation (and not knowledge), 'we' (as brain-sign) cannot understand what neural material, or any material, is. Neuroscience is a study of the brain effected by the brain. Brain-sign is derivative, not primary. Towards the end of his life Thomas Kuhn wrote:

"Understanding the process of evolution has in recent years seemed increasingly to require conceiving the gene pool, not as the mere aggregate of the genes of individual organisms, but as itself a sort of individual of which the members of the species are parts. I am persuaded that this example contains important clues to the sense in which science is intrinsically a community activity" (1993, p. 329).

With some elements missing, this is brain-sign theory's position.

\section{LANGUAGE, SCIENCE AND BELIEF}

So far brain-sign has been characterized as arising within organisms as a target for collective action. But that kind of causal orientation is not the only mechanism for communication. ${ }^{22}$

Language has crucially differentiated human beings from other creatures both by meaning and communication. Language is significant because, in our seeing and hearing of it, we supposedly understand categories and arrangements of the world, express our feelings and sympathize with those of others, and we order the world in mathematics and science.

However, in the words of Paul Horwich: "Each expression of language surely means something - there is some fact as to what it means; but the nature of such facts is notoriously obscure and controversial" (2005, p. 1). As with consciousness, language is scientifically opaque. How can it grasp the world and represent it? How do we reason by language? What is the meaning of meaning? How can words cause us to act in the world?

Meaning and understanding are interdependent mentalist categories. The word 'tree' is grasped by our understanding, and it is via understanding that the meaning of 'tree' is identified. But the brain-sign concept eliminates these terms because they are an explanatory dead end. The reason for the controversy, the theory proposes, is that we have not acknowledged language as a physical phenomenon. What does it do as physicality? From what has been said, a straightforward account can be developed.

Language cannot be heard or seen: hearing and seeing are unscientific categories. Language functions by one brain altering the causal orientation of another via the physical intermediaries of compression waves or electromagnetic radiation. My brain can alter the causal orientation of your brain by generating the spoken or graphical intermediaries of the word 'tree'. Your brain interprets its resulting causal state to signify its orientation: hence 'you' become the brain-sign 'tree', which 'you suppose' is hearing or seeing the word. That we 'take ourselves' to 'understand' the word 'tree' is brain-sign effecting its communicative function - of being in a common state with others. Our brains have been trained by those around us from our earliest days to link their causal orientation towards actual trees with the

\footnotetext{
${ }^{22}$ The term 'unit of the communicated' covers different kinds of collective interaction. An individual A signifying 'pain', evident in expression, action or 'statement', causally invokes biological responses in others, which may include help. B's brain is thus altered in relation to individual A. It is likely that individual B's brain generates brain-sign states which signify the negative effects of 'pain', if not 'pain' itself. Hence the mentalist notion of 'empathy'. For a mentalist review and references, see Prinz (2012), Body Schemes, p. 73 and below.
} 
causal impact of the intermediaries (electro-magnetic radiation and compression waves) of the word 'tree', and thus 'we' become the communally held brain-sign state of 'tree'. What may be additionally evoked in each brain as 'images' of trees etc., depends upon neural linkages within our individual brains.

As the brain-sign 'image' of the tree facilitates our collective interaction with an actual tree, so our mutual brain-sign of the word 'tree' may also facilitate our actions. (This is a scientific account of Searle's functionally obscure notion of our agreement about consciousness in section 2B.) These two brain-sign states are therefore of equivalent functional status. By contrast mental seeing of the world is different from mental language because they serve different mental functions, i.e. different faculties with different kinds of causality. ${ }^{23}$

\subsection{The benefits of language - science}

Why is language, in brain-sign terms, beneficial for collective survival? Consider the nature of science. The brain trains itself causally to interact with the world. But science has developed through the work of numerous brains, as Kuhn indicates. Causal states of brains cannot be shared: they are uniquely held in neural fabric. The biological requirement is for (appropriate) causal states to be re-presented in a form sharable between brains.

Einstein's brain adapted until causally orientated toward its/his problem. When so orientated, it self-interpreted as the brain-sign $E=m c^{2}$ (a sentence, not a word). Then he wrote it down. Learning the equation $E=m c^{2}$ requires sharable states which do not start on the page. They start as causal states in the brain, which are neurally interpreted as brain-sign states. These are not written in the brain as the equation on the page but, as signs of the causal states of the brain, they are sharable.

\subsection{The limits of language}

Of course, the degree to which $E=m c^{2}$ signifies effectively in a brain depends upon the specificity of the brain's causal orientations which, in Einstein's case, resulted from considerable restructuring neural work. Moreover, each element of the equation signifies a causal orientation toward the world in its own right (for energy, mass, the speed of light and equals) which, assembled as the formula, generates an effective causal integration only if the elements themselves are causally adequate. Thus merely to 'say' $E=m c^{2}$ does not necessarily signify an effective result as science.

In general, although language functions by its commonality between brains, that may not result from an adequate causal identity in each brain: effective action may therefore not take place. Hence the mentalist notion of misunderstanding or miscommunication. Words are a spare, and therefore imprecise, inter-neural representation in relation to the complex causal conditions of the brain. Nonetheless, language is the most elaborate biological communication method that has evolved.

The notion that there is a Language of Thought (LOT), ${ }^{24}$ by contrast, as which (for example) reasoning takes place by words themselves, concretized as mental symbols in the brain, seems remote from a neuroscientific description of brain function, reifying, as it does, the hypothesized thinking process.

Why are words arbitrary (as Saussure said, 1970)? Why can humans operate with different languages and scripts? The transmission of language alters the causal orientation of another brain. It does not generate a mental understanding. (We do not understand the same thing in different languages. ${ }^{25}$ As long as the brain's causality results in the same neural interpretation

\footnotetext{
${ }^{23}$ The unexplained causalities at the heart of the mind-body problem.

${ }^{24}$ Developed in its early days by, amongst others, Jerry Fodor. Recent approaches include those of Susan Schneider (2011).

${ }^{25}$ W.V.O. Quine's 'indeterminacy of translation' is a misconstrual of the fundamental properties.
} 
within the community (which it will do by social training), in principle, 'words' may be anything. ${ }^{26}$ For example: sea, $\theta \dot{\alpha} \lambda \alpha \sigma \sigma \alpha$, 海.

It will be appreciated that while 'image' and language brain-signs are functionally the same (section 6.0), the former, while a brain creation, is directly derived from the causal state of the brain toward the world and functions as a target between organisms. The latter is a brain creation (including what are termed generalization and syntax) whose causal properties, from which the brain-sign derives, have evolved to alter the causal orientation of another brain in a more complex way than other species (e.g. bird song). Even so, brain-sign 'image' and brainsign language, in performing the same function, both 'appear to us' with the same character existing as the world (or universe) of our experience.

\subsection{Neural theorizing}

We have defined brain-sign as an explanation of the world cause of the brain's causal orientation. We can extend that by calling each brain-sign a neural theory about the world. One might describe the causal orientation itself a theory, for the causality is based upon a limited yet (often) effective relation to the world. Of course, one would not generally term the causal state a theory since it is purely causal. However, once it is neurally interpreted into brain-sign, as for example $E=m c^{2}$, we do have a neural theory. For lion brains the gazelle is a proto-theory about what in the world is the target for the hunt. 'Proto' because lions cannot communicate explicitly with each other about it.

That brain-sign can be termed only a theory (not knowledge, not a manifestation of consciousness), does not result from the mind being in the head whereas the world is outside the head. It results from the neural method of its creation, i.e. from the brain's limited causal orientation toward the world, and serving communication only.

\subsection{Mental beliefs}

Beliefs are generally regarded as important factors in the behavior of humans. Although they may not necessarily be expressed directly in an action, they can be understood to underlie the motivation or cause of action. However, as brain-sign, what are called beliefs signify the causal orientation of brains, not mental motives.

Because one brain can modify another's causal orientation by language intermediaries, it can dominate them. Thus it 'appears to us' that there are shared causal beliefs. What is shared, however, is causal orientation. 'Beliefs' are not causal. For example, early Christianity absorbed Greek philosophy, e.g. Platonic Ideas, not by mentally integrating beliefs, but by the inculcation of causal orientations neurally interpreted as language brain-signs. It was the encounter of the brains of Christian theorists with the inter-neural intermediaries (electromagnetic and compression waves) of Plato's writings that generated the associated causal orientations. Neither realm of 'belief' had any causal significance.

Specifically, for the theory presented here, the reader (as a mental I) does not decide, by reading the text, to retain consciousness or adopt brain-sign as a believed theory, for there is no mentalist function of decision, adoption or belief. 'We' (as brain-sign) are one or other (or neither) as derived from our causal orientation. The 'sense of choice' as 'belief' is an aspect of the brain-sign of our brain's sustained causal orientation.

But a related point should be added. Both theories, viz. consciousness and brain-sign, are the brain's self-explanation of its function and derived from its causal orientations. Whereas brain-sign theory acknowledges this, with its inherent biological limitations, consciousness theory claims it is knowledge, the brain's 'self-conviction' that it has the power to (e.g.) see the

\footnotetext{
${ }^{26}$ Saussure actually proposes that the word unites with a concept. However, concepts, in brain-sign terms, are on the same level as words. That is, the expression of a 'concept' is still related to associated causal orientations of the brain which the expression signifies.
} 
world. Thus consciousness, as a neural self-explanation, 'legitimizes itself' by a maintained neural state from which the theory derives. By self-interpreting as consciousness theory, 'we' (as brain-sign) cannot 'think' otherwise, i.e. be brain-sign theory.

But knowledge, in this case our knowledge that we are conscious, is scientifically inexplicable. Brain-sign theory, on the other hand, explains the existence of the theory of consciousness (as neural self-explanation), and itself from purely physical conditions. What is required to install brain-sign theory is a change in the brain's sustained causal orientation, and thus its self-interpretation as brain-sign theory.

In this way brain-sign theory is the ur-theory - of explanation, or theory itself.

However, although 'we' may 'state' we have specific 'beliefs', and these do signify causal orientations of the brain, that does not necessarily mean our brains will act accordingly. Neural signification may operate for a different function than collective uniformity in an act for example, as a 'joke' or a 'lie'.

Creating a new causal orientation towards the world, and thus a new theory (or 'belief') about the world, including ourselves as part of the world, is a reconstructive causallyorientated mechanism of the brain, as in the Einstein example. Locating this process in neural fabric is of great interest for the creative process itself.

The brain-sign account of the inculcation of 'beliefs' supersedes Richard Dawkins' beliefcentered meme theory, because that depends on consciousness. ${ }^{27}$

\subsection{Unimplemented neural causal orientation}

Why would Damasio state that consciousness offers "the world of planning, the world of formulation of scenarios and prediction of outcomes" (section 3)? Because consciousness apparently generates these states without direct action. Brain-sign theory puts this differently. It proposes that the brain constructs alternative causal neural structures which, in principle, may be implemented as a programmed readiness for action. They may not be implemented because they do not relate directly to current conditions of the organism in the world, or are neurally deselected. Hence 'we' (as brain-sign) have the 'sense' that we do construct scenarios and plans.

Scientifically, the difference between Damasio's consciousness theory and brain-sign theory is that brain-sign is justified by its derivation from the brain's causal role. Consciousness has no equivalent justification. In Damasio's words, it is "the latest and most sophisticated means of generating adequate responses." Sophistication is not a justification. 28

However, 'justification' is still a brain-sign. What counts in brain function is the neural causal orientation it signifies: hence Damasio's 'words' about consciousness, and the 'words' here concerning brain-sign. I.e., brain-sign 'justification' is still derived from the way one brain can alter others. 'We' never escape being the result of neural causality.

\section{WHAT DOES IT MEAN TO DIE?}

Finally, in considering the nature of death, I wish to convey the radical bio-functional alteration of our self-image. As brain-sign 'we' do not know 'we' are alive, and 'we' do not know 'we' will die, whatever our brains cause 'us' to say.

Our natural response to this may be derision. What could be more certain than this knowledge? But herein lies the core of the mentalist problem: it is almost impossible to deny what appears so self-evident. But it is the inevitability of our 'conviction' (and 'derision') that

\footnotetext{
${ }^{27}$ Indeed, Dawkins states: "Each one of us knows, from the evidence of our own introspection, that, at least in one modern survival machine [i.e. humans]... purposiveness has evolved the property we call 'consciousness'. I am not philosopher enough to discuss what this means" (1989, p. 50).

${ }^{28}$ Edelman and Tonini's dense neuronal group theory similarly lacks physical justification (section $2 \mathrm{~B}$ ).
} 
renders inter-neural communication. We cannot appreciate, in the natural disposition, how we function as purely physical organisms.

In a supposedly scientific way, it might be said that the fear of dying derives from the biological aim of keeping us alive. But biology has no aim, which is a mentalist notion. What manufactures fear? Some say it is the brain, but then do not explain fear as a physical state. Some propose the brain creates virtual states (for example fear) as which it 'decides' how to act. But this demands our so-called experience be justified by the explanatory extreme of an artificial yet causal world (i.e. consciousness) of our brain's invention. No underpinning biology supports this. Yet unless we can identify fear as a physical state, we deny the universe is entirely physical - which some may.

The more straightforward answer is that fear does not exist. The brain feels nothing, and it fears nothing. It is a physical object. Life, so-termed, is an assembly of lifeless material. However, its functioning as individual units (organisms) can be vastly enhanced by their grouping into larger physical units. There are numerous reasons for this, from the pure survival chances of the individual in a crowd, to the distribution of precise skills across a wide population which enhances the survival of all. ${ }^{29}$

The 'feeling of fear'about death (as brain-sign) might appear to be our brain's explanatory response in the collective about our inevitable demise. But the 'feeling' state is not ontologically primary. It is a sign derived from our brain's causal orientation. That 'we will die' is a neural theory of our future state, as is 'the future' itself. We cannot simply substitute brain-sign states for mental states - as if they had explanatory content for ourselves about some specific idea or concept of a world we know. They must be couched in a different way since they derive from causal orientations of the brain, which requires a new explanatory science.

Thus even as communication we cannot say the idea of death lies at the foundation of our 'fear'. An idea is an unexplained mentalist construct, as is its subject, death. We must show how a sign emerges as a sign, and nothing more. One possibility is that, for death, we substitute an 'imagined' simulation of darkness and being entirely alone. But still we must derive these terms from purely physical conditions, for the signification of death as darkness and being alone is still derived from operative circuits of the brain (and not mentalist imagination). Towards what are they causally orientated?

The brain-sign state signifies a causal orientation towards the absence of the biological conditions which the brain has evolved to fulfill: Action - which (generally) cannot be executed without, for the optically normal, electromagnetic radiation, which is a means of physical access to the world (and neurally signified as light); and No Other to communicate with about action (i.e. isolation). The brain-sign state supposed as fear of death would be, therefore, not about the idea of the loss of life, but rather the signification of the causal conditions of the brain in which its biological raison d'être is nullified - lack of electromagnetic radiation, and the absence of others. The brain does not know this in its momentary causal conditions. It simply exists in a nullified state of total inaction, signified as our current brainsign state.

That state can now be wholly identified as a derived sign. Light does not exist: it is a construct of the brain signifying the general possibility of action with other brains via electromagnetic radiation. (That is the function of 'what we take as' light, and suppose exists in the world to which, as brain-sign, we have in fact no access.) Our social world does not exist: it is a brain construct signifying the possibility and actuality of collective action with other brains. That is the function of, for example, the bodily presence of you to me as occurring in my supposed experience.

In signifying the brain's nullified state, therefore, 'darkness' and 'being alone' are apposite brain-signs. Yet they cannot be stable or precise since the brain cannot nullify itself conclusively: that is beyond its function. Thus the brain-sign 'taken' as fear does not derive

${ }^{29} \mathrm{I}$ will not here approach the topic of evolutionary selection criteria. 
from darkness and being alone (one brain-sign cannot cause another); it signifies the negative 'sense' of our body's (our organism's) total inability to act alongside (i.e. together with) a vague 'sense' of darkness and being alone. This is borne out by our natural disposition when we say: "I can't imagine what it would be like to be dead." Our natural disposition does not derive from a failure of imagination (which does not exist), but our neural/causal limitations from which brain-sign is constructed, as which we say "I cannot imagine...".

However, once brain-sign theory is adopted by the brain as its causal self-explanation rather than consciousness, the 'fear of death' is mightily reduced because it resulted from an erroneous interpretation by the brain as mental states. Dying will not deprive us of something we had before (mental existence), because our brains no longer self-explain that way. 'We' (as brain-sign) no longer 'imagine' a death which does not exist. Indeed, because meaning does not exist, death means nothing. ${ }^{30}$

\section{REFERENCES}

Baars, B. (1997). In The Theatre of Consciousness. Journal of Consciousness Studies, 4, 292-309. http:/ / www.imprint.co.uk/theatre.htm

Bennett, M., Hacker, P. (2003). The Philosophical Foundations of Neuroscience. Blackwell Publishing.

Chalmers, D. (1995-7). Facing up to the Problem of Consciousness. In Explaining Consciousness: The Hard Problem, 9-32. Ed. J. Shear. A Bradford Book, MIT Press, (and the Journal of Consciousness Studies).

Churchland, P. (1981) Eliminative Materialism and the Propositional Attitudes. The Journal of Philosophy, 2, 67-90.

Churchland, P. (2007). Neurophilosophy at Work. Cambridge University Press.

Clapson, P. (2012). The world without knowledge: The Theory of Brain-Sign. Durham University: http://etheses.dur.ac.uk/3560/

Crick, F., \& Koch, C. (1990). Towards a neurobiological theory of consciousness. Seminars in the Neurosciences, 2, 263-275.

Damasio, A. (1999). The Feeling of What Happens. William Heinemann.

Dawkins, R. (1989). The Selfish Gene, Oxford University Press.

Eagleman, D. (2011). Incognito: The Secret Lives of the Brain. Canongate.

Edelman, G. \& Tononi, G. (2000). Consciousness: How Matter Becomes Imagination, Penguin.

Gibson, J. J. (1977). The theory of affordances. In R. Shaw \& J. Bransford (Eds.), Perceiving,acting, and knowing: Toward an ecological psychology,67-82. Hillsdale, NJ: Erlbaum.

Horwich, P. (2005). Reflections on Meaning. Oxford: Clarendon Press.

Hurley, S. (2008) The shared circuits model (SCM): How control, mirroring, and simulation can enable imitation, deliberation, and mind reading. Behavioral and Brain Sciences, 31, 1-58.

Jackendoff, R. (1987). Consciousness and the Computational Mind. Cambridge, MA: MIT Press.

Kuhn, T. (1993). Afterwords. In World Changes: Thomas Kuhn and the Nature of Science. Ed. P. Horwich. A Bradford Book, MIT Press, 311-341.

Kuhn, T. (1996) The Structure of Scientific Revolutions, $3^{\text {rd }}$ edition. University of Chicago Press.

Lauer, Q. (1965). In Husserl, E. Phenomenology and the Crisis of Philosophy. Trans. Quentin Lauer. Harper Tourchbooks.

Machamer, P (2009). Learning, Neuroscience, and the Return of Behaviorism. In The Oxford Handbook of Philosophy and Neuroscience. Ed. J. Bickle. Oxford University Press, 166-178.

Mareschal, D., Johnson, M., Sirios, S., Spratling, M., Thomas, M., Westerman, G. (2007). Neuroconstructivism: How the Brain Constructs Cognition. Volume One. Oxford University Press.

McGinn, C. (1989). Can We Solve the Mind-Body Problem?. Mind, 98: 349-366.

\footnotetext{
${ }^{30}$ It is interesting to compare the account given of the wholly physical existence of the human being and its (non-) knowing relation to death, with that of Derek Parfit in a famous passage from his book Reasons and Persons. Parfit's position is based upon the positive effect of making the human being reducible to physical conditions, along with psychological continuity, and that our continued existence is not considered a further fact. As a result, he says: "The truth is very different from what we are inclined to believe.... I now live in the open air.... Other people are closer... When I believed the Non-Reductionist View, I also cared more about my inevitable death.... Now... my death seems to me less bad" $(1984$, p. 281).The brain-sign account (as scientific theory) adds significantly to Parfit's view by demonstrating what happens when the mentalist hypothesis (in which Parfit includes psychological continuity) is wholly eliminated. The conclusions are remarkably similar.
} 
Nietzsche, F. (1961). Thus Spoke Zarathustra. Trans. R.J. Hollingdale. Penguin.

Parfit, D. (1984). Reasons and Persons. Particularly Part Three: Personal Identity Chapter 13. Clarendon Press: Oxford.

Penrose, R. (1989). The Emperor's New Mind, Oxford Press, Oxford.

Pessoa, L. (2013). The Cognitive-Emotional Brain. MIT Press.

Prinz, W. (2012). Open Minds: The Social Making of Agency and Intentionality. MIT Press.

Saussure, F. de (1970). On the Nature of Language, reproduced in Lane, M. (ed.) Structuralism, A Reader, Jonathan Cape. From Course in General Linguistics (1959) trans. W. Baskin, Philosophical Library, New York

Schneider, S. (2011). The Language of Thought: a New Direction. MIT Press.

Searle, J. (1998). The Mystery of Consciousness. Granta Books.

Searle, J. (2007). Putting Consciousness Back in the Brain. In Neuroscience and Philosophy. Columbia University Press, 97-124.

Searle, J. (2011). The Mystery of Consciousness Continues. The New York Review of Books, June 9.

Sellars, W. (1997). Empiricism and the Philosophy of Mind. Harvard University Press. (First published in Minnesota Studies in the Philosophy of Science, 1956).

Semin, G.R., Echterhoff, G. (2010). (eds) Grounding Sociality: Neurons, Mind and Culture. Psychology Press.

Seth, A.K., Barrett, A.D., \& Barnett L. (2011). Causal density and integrated information as measures of conscious level. Phil. Trans. R. Soc. A.369: 3748-3767.

Shea, N., et al. (2014). Supra-personal cognitive control and metacognition. Trends in Cognitive Science, 18,4: 186-193.

Varela, F. J., Thompson, E., \& Rosch, E. (1991). The Embodied Mind. MIT Press.

Wilson, E. O. (2012). The Social Conquest of Earth. Liveright Publishing Corporation. 